\title{
The Underutilization, Adverse Reactions and Efficacy of Statins after Liver Transplant: A Meta-Analysis and Systematic Review
}

\author{
Yeung Jek Ho ${ }^{1}$, Audrey Su-Min Koh ${ }^{1}$, Zhi Hao Ong ${ }^{1}$, Cheng Han Ng ${ }^{1, * \mathbb{D}}$, Gwyneth Kong ${ }^{1}$, \\ Nicholas W.S. Chew ${ }^{2} \mathbb{D}$, Hui Ning Lim ${ }^{1}$, M. Shadab Siddiqui ${ }^{3}$ and Mark Dhinesh Muthiah ${ }^{1,4, *}$ \\ 1 National University Centre for Organ Transplantation, National University Health System, \\ Singapore 119074, Singapore; hoyeungjek@u.nus.edu (Y.J.H.); audrey_koh@u.nus.edu (A.S.-M.K.); \\ ong.zhihao@u.nus.edu (Z.H.O.); e0326129@u.nus.edu (G.K.); hui_ning_lim@nuhs.edu.sg (H.N.L.) \\ 2 National University Heart Centre, Department of Cardiology, National University Hospital, \\ Singapore 119074, Singapore; nicholas_ws_chew@nuhs.edu.sg \\ 3 Division of Gastroenterology and Hepatology, Virginia Commonwealth University, \\ Richmond, VA 23284, USA; mohammad.siddiqui@vcuhealth.org \\ 4 Division of Gastroenterology and Hepatology, Department of Medicine, National University Hospital, \\ Singapore 119074, Singapore \\ * Correspondence: e0360747@u.nus.edu (C.H.N.); mdcmdm@nus.edu.sg (M.D.M.); \\ Tel.: +65-6772-4354 (M.D.M.)
}

Citation: Ho, Y.J.; Koh, A.S.-M.; Ong, Z.H.; Ng, C.H.; Kong, G.; Chew, N.W.S.; Lim, H.N.; Siddiqui, M.S.; Muthiah, M.D. The Underutilization, Adverse Reactions and Efficacy of Statins after Liver Transplant: A Meta-Analysis and Systematic Review. Transplantology 2021, 2, 264-273. https://doi.org/10.3390/ transplantology2030025

Academic Editors: Alessandro Parente and Vincenzo Ronca

Received: 31 May 2021

Accepted: 25 June 2021

Published: 3 July 2021

Publisher's Note: MDPI stays neutral with regard to jurisdictional claims in published maps and institutional affiliations.

Copyright: (c) 2021 by the authors. Licensee MDPI, Basel, Switzerland. This article is an open access article distributed under the terms and conditions of the Creative Commons Attribution (CC BY) license (https:// creativecommons.org/licenses/by/ $4.0 /)$
Abstract: (1) Background: Treatment of dyslipidemia via statin therapy in the non-liver transplant (LT) population is associated with a mortality benefit; however, the impact of statin therapy in post-LT population is not well-defined. This meta-analysis seeks to investigate the safety and efficacy of statin therapy in post-LT patients. (2) Methods: A systematic literature search on Medline and EMBASE database was conducted. A single-arm proportional meta-analysis and conventional pairwise meta-analysis were performed to compare different outcomes with a random effects model. (3) Results: A total of 11 studies were included in this study, with 697 LT recipients identified to be on statin therapy. Statins were underutilized with only 32\% (95\% CI: 0.15-0.52) of 1094 post-LT patients on therapy. The incidence of adverse events of $14 \%$ (95\% CI: $0.05-0.25)$ related to statin therapy was low. A significant mortality benefit was noted in patients on statin therapy with $\mathrm{HR}=0.282$ (95\% CI: $0.154-0.517, p<0.001)$, and improved lipid profiles post LT. The use of statins also significantly decreased odds of graft rejection (OR $=0.33$; 95\% CI: 0.15-0.73) and hepatocellular carcinoma (HCC) recurrence ( $\mathrm{HR}=0.32,95 \%$ CI: 0.11-0.89). (4) Conclusions: Statin therapy is safe and efficacious in post-LT patients. Future studies to evaluate the effects of interactions between statins and immunosuppressant therapy are warranted.

Keywords: hyperlipidemia; post-liver transplant; statin; graft rejection

\section{Introduction}

Hyperlipidemia in post-LT patients is a common complication, occurring in $27-71 \%$ of liver-transplant recipients [1-3], and is an important risk factor for cardiovascular disease (CVD). The risk of cardiovascular (CVS) events in post-LT patients was found to be approximately $64 \%$ higher than in the general population [4] and was associated with non-raft-related morbidity and mortality in liver-transplant patients [5,6]. In addition, hyperlipidemia is also associated with impaired graft function and reduced graft survival [3,7]. Hence, early and effective management of hyperlipidemia is important in preventing CVD and graft dysfunction [3].

While statins have been proven safe in the general population [8], this remains unclear in the setting of transplant patients, with several observational studies showing varied results in outcomes such as mortality and adverse reactions [9-11]. Statins are 3hydroxy-methylglutaryl coenzyme A reductase (HMG-CoA) inhibitors widely prescribed to treat hyperlipidemia by reducing the rate limiting step in cholesterol biosynthesis, and 
one of the major limitations of the drug lies in its metabolism by cytochrome P4503A4 with potential interactions with calcineurin inhibitors, the backbone of liver-transplant immunosuppression [6,12]. Given the fear of potential drug interactions, inappropriate withholding of statins in post-LT patients with hyperlipidemia is common $[13,14]$.

While several meta-analyses have been conducted in renal and cardiac transplantations [15-18], meta-analyses on the use of statins in liver transplants has been limited, as statins are still withheld in post-LT patients. The disparity in the use of statins could partially be attributed to the perceived increased risk of statin-induced hepatotoxicity $[13,19]$. This meta-analysis seeks to investigate the safety, tolerability, and efficacy of statin therapy in reducing lipid levels and CVS events in post-LT patients.

\section{Materials and Methods}

\subsection{Search Strategy}

The review was synthesized with reference to the Preferred Reporting Items for Systematic Reviews and Meta-Analyses (PRISMA) recommendations. A literature search was conducted on 15 December 2020, and relevant publications were identified by a search on Medline and Embase electronic databases using Boolean operators in "statin" and "liver transplant" in conjunction with a medical librarian. The search terms included "(exp Antilipemic Agents/or (statin* or atorvastatin or fluvastatin or lovastatin or pitavastatin or pravastatin or rosuvastatin or simvastatin or HMG coA or fibrate* or niacin* or PSK9 or Ezetimibe or cholestyramine).tw. or lipid lowering.tw.) AND (((liver* OR hepat*) adj3 (transplant* OR graft*)).tw. or exp Liver Transplantation/)". Identified references were imported into Endnote X9, and duplicates were removed.

\subsection{Study Selection and Extraction}

The titles and abstracts of papers were screened by two authors. The inclusion criteria comprised the use of statin in post-liver-transplant settings and included studies assessing the utilization, adverse events and benefits of statin use. The restriction to the use of only statin was to maintain homogeneity, and only one article used lipid-lowering medications besides statin [20]. Randomised controlled trials, randomised cross-over trials, cohort studies, and prospective trials were eligible for inclusion. Conference abstracts were deemed appropriate for inclusion in this study [21,22] as recommended by the Cochrane Group to reduce publication bias $[23,24]$. Duplicate articles using the same cohort of patients in their analysis were excluded. Subsequently, data were extracted from the relevant studies by two blinded authors. The domains extracted included the baseline demographics (author, year, country of study, follow-up duration, sample size, age and gender), intervention (statin name) and associated outcomes (utilization, adverse reactions, change in cholesterol levels, CVS events, mortality, graft rejection, hepatocellular carcinoma (HCC) recurrence and new-onset diabetes after transplantation (NODAT). The adverse reaction of myopathy was defined as increased creatinine phosphokinase (CPK) with pain, while myalgia/muscle cramps was defined as pain without increased CPK) [9]. Estimated values of the mean and standard deviation were derived using formulas devised by Wan et al. and Furukawa et al. when they were not provided [25,26].

\subsection{Statistical Analysis and Quality Assessment}

The statistical analysis of included articles was performed with single arm proportional meta-analysis and conventional pairwise analysis in random effects in RStudio (4.0.3) (Boston, MA 02210, USA) and STATA 16.1 (College Station, Texas 77845, USA). Single arm proportional meta-analysis was performed after a Freeman-Turkey double arcsine transformation to stabilize the variance [27], and effect sizes were pooled by the DerSimonian and Laird model [28]. In the analysis of dichotomous variables, the DerSimonian and Laird random effects model was used to pool outcomes in odds ratio (OR) $[29,30]$. Quantification of heterogeneity was measured using the $\mathrm{I}^{2}$ and Cochran $\mathrm{Q}$ test and a value of $<40 \%$ and $p>0.10$ was considered statistically significant for heterogeneity [28]. 
Regardless, all measures were pooled in random effects as a more robust measure of the true effect compared to the fixed effect model. Publication bias was not conducted as there were insufficient articles $(\mathrm{k}<10)$ for a meaningful analysis either from funnel plots or Egger's/Begg's regression [22]. When insufficient studies were available in the analysis of outcomes, a systematic reporting of results was deemed appropriate in the presentation of results. Due to the largely observational nature of included studies, quality assessment of included articles was considered with the Joanna Briggs Institute (JBI) Critical Appraisal Tools [31]. The JBI is the most widely used tool in prevalence meta-analysis to assess quality of included articles based on the methodology rigor and appropriate statistical analysis [32].

\section{Results}

\subsection{Summary of Included Articles}

Based on search strategy and selection process, 915 articles were identified and 64 underwent a full-text review. At the end of the selection process (Figure 1), only 11 studies fulfilled the criteria necessary to be included in the analysis [9-11,33-40]. Of the 11 [9-11,33-40] studies that discussed the use of statins in post-LT patients, a total of 4 articles were conference abstracts [11,36-38]. A total of 697 patients from these studies were identified to be on statin therapy. Among the 11 studies included, 6 were conducted in North America [9,11,33,37,38,40], 2 in Europe [34,36], 2 in Asia [10,39] and 1 [35] in Australia. The most common statin used was pravastatin, with statins in 6 studies undefined. Among the included studies, only 3 studies were included that reported mammalian target of rapamycin (mTOR) inhibitor usage; 49 patients (5.57\%) were on mTOR inhibitors. Quality assessment score range from 4 to 11 . Table 1 summarizes the characteristics of included articles.

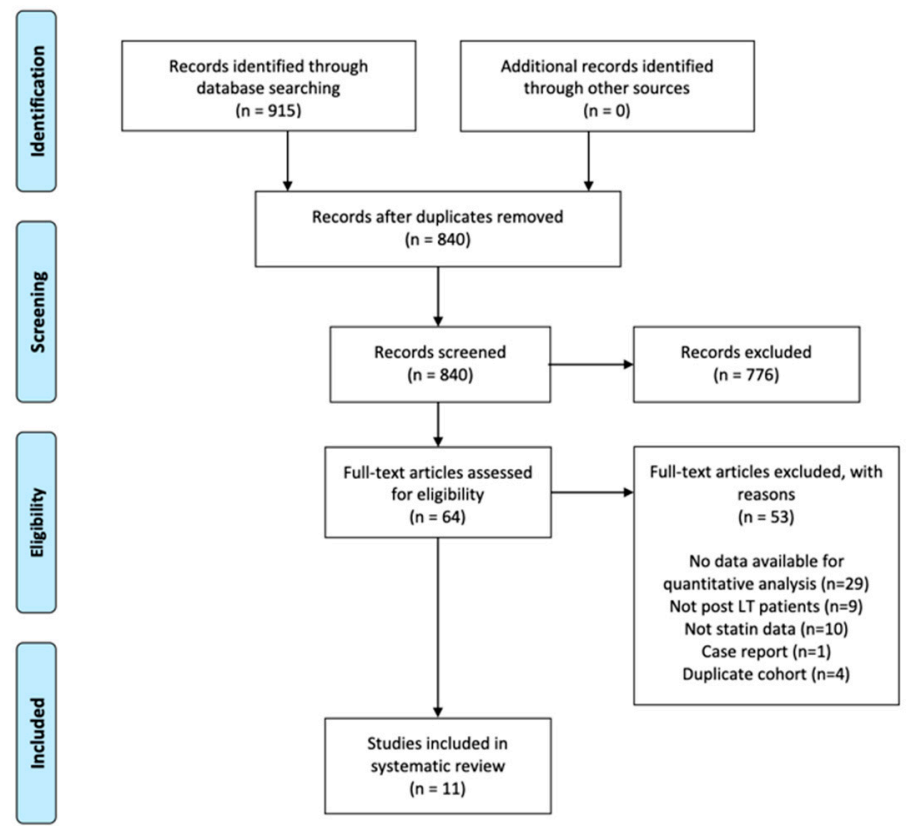

Figure 1. PRISMA flow diagram of included articles. 
Table 1. Summary of Included Studies.

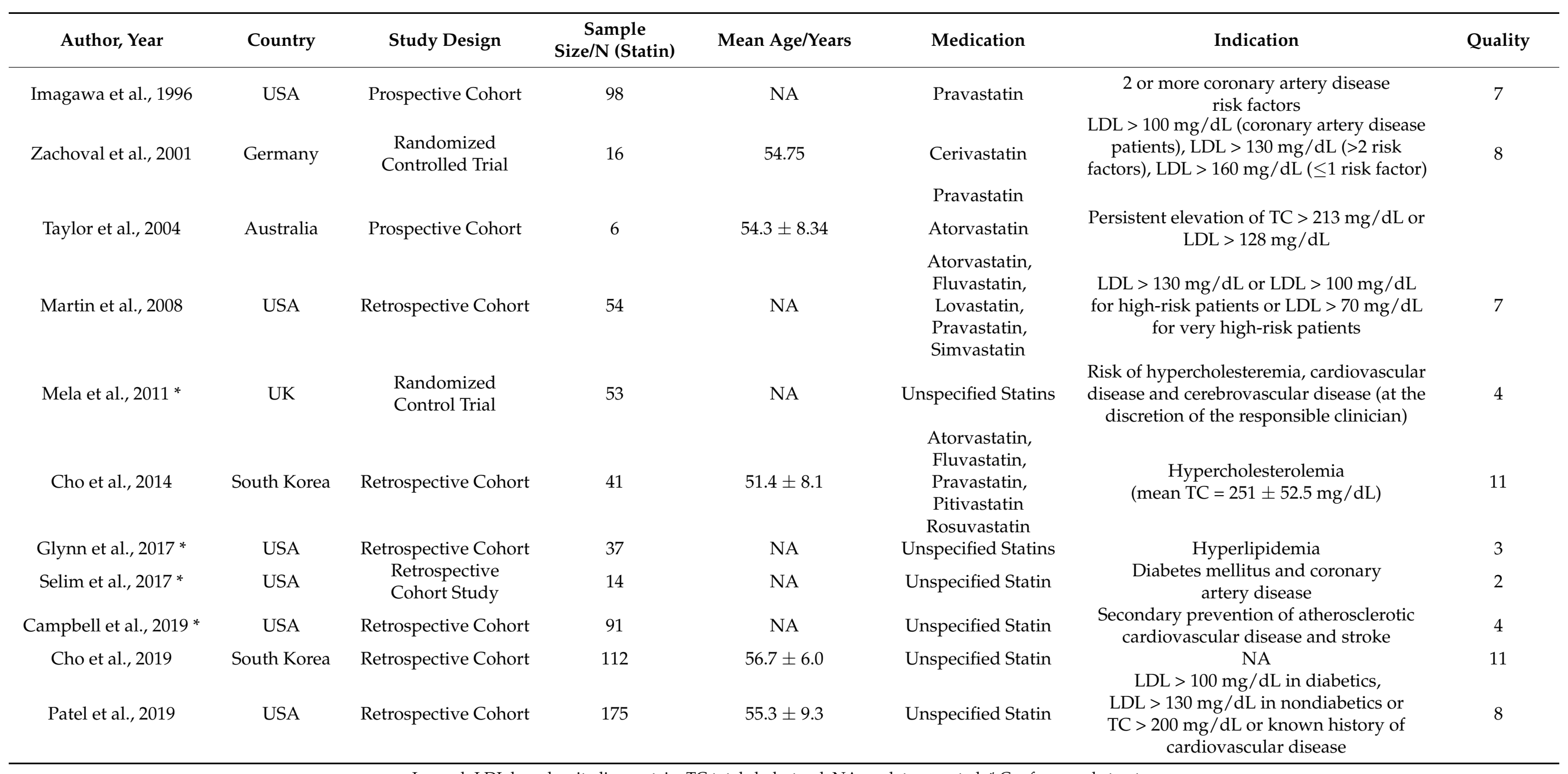




\subsection{Indications and Utilization}

The most common indications for statin therapy were hypercholesterolemia or the presence of coronary artery disease (CAD) risk factors [9,10,33-35,40]. Across 4 studies [11,37,38,40], the pooled proportion of patients with statin use in post-LT settings was 32\% (95\% CI: $0.15-0.52$, Figure 2) in a total of 1094 patients who were indicated for statins.

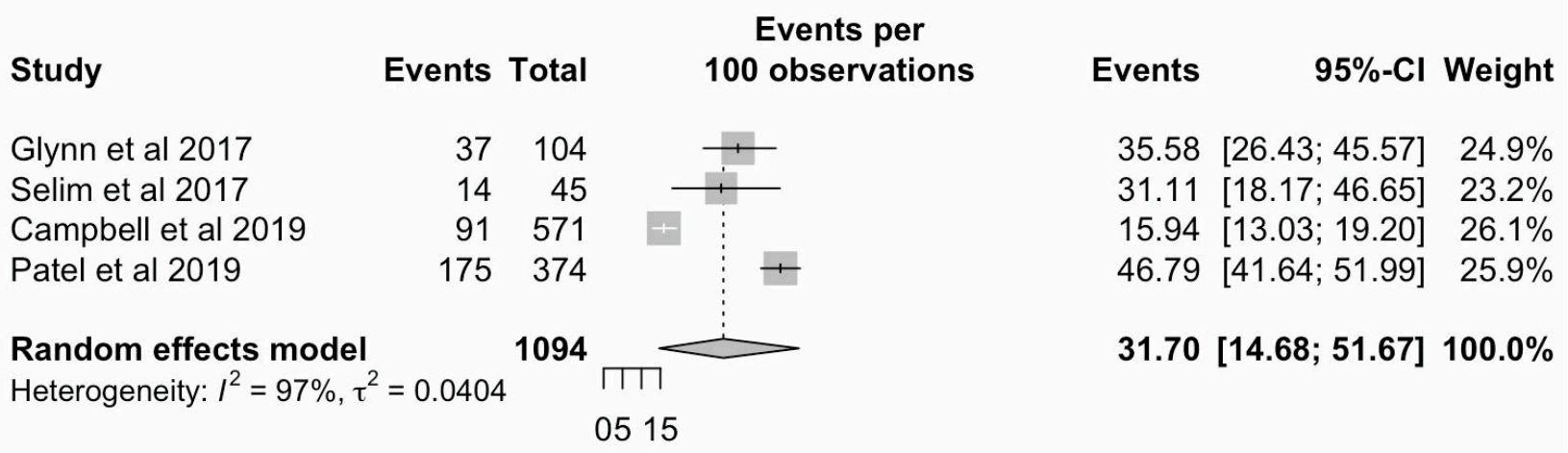

Figure 2. Forest plot on the utilization of statins.

\subsection{Adverse Events}

A total of $14 \%$ (95\% CI: $0.05-0.25$, Figure 3) of individuals experienced an adverse event with statin use in 443 patients. The incidence of myopathy was $2 \%$ (95\% CI: $0-0.10)$ in 54 patients. Myalgia/muscle cramps were experienced by 5\% (95\% CI: $0.02-0.08$ ) of 364 patients. In 98 patients, the incidence of nausea and vomiting, GI side effects and pruritus was 3\% (95\% CI: $0.01-0.09), 2 \%$ (95\% CI: $0.01-0.07)$ and $1 \%$ (95\% CI: $0.00-0.06)$, respectively. The incidence of NODAT was 32\% (95\% CI: $0.20-0.47$ ) in the 41 patients assessed, while graft rejection had an incidence of 9\% (95\% CI: $0.04-0.20)$ in a total of 136 patients assessed. Statins were discontinued in $13 \%$ (95\% CI: $0.05-0.23$ ) of patients, of which the majority were due to adverse events and poor compliance.

\begin{tabular}{|c|c|c|c|c|c|c|}
\hline Study & Events & Total & $\begin{array}{c}\text { Events per } \\
100 \text { observations }\end{array}$ & Events & $95 \%-\mathrm{Cl}$ & Weight \\
\hline Imagawa et al1996 & 8 & $98+$ & & 8.16 & {$[3.59 ; 15.45]$} & $14.9 \%$ \\
\hline Zachoval et al (arm 1)2001 & 0 & $16 \longmapsto$ & & 0.00 & {$[0.00 ; 20.59]$} & $10.9 \%$ \\
\hline Zachoval et al (arm 2)2001 & 0 & $16 \longmapsto$ & & 0.00 & {$[0.00 ; 20.59]$} & $10.9 \%$ \\
\hline Taylor et al2004 & 1 & 6 & & 16.67 & {$[0.42 ; 64.12]$} & $7.2 \%$ \\
\hline Martin et al2008 & 6 & $54 \div$ & & 11.11 & {$[4.19 ; 22.63]$} & $14.0 \%$ \\
\hline Cho et al2014 & 13 & 41 & + & 31.71 & {$[18.08 ; 48.09]$} & $13.5 \%$ \\
\hline Glynn et al 2017 & 20 & 37 & 1 & 54.05 & {$[36.92 ; 70.51]$} & $13.3 \%$ \\
\hline Patel et al2019 & 21 & 175 & & 12.00 & {$[7.58 ; 17.76]$} & $15.4 \%$ \\
\hline \multirow{2}{*}{\multicolumn{2}{|c|}{$\begin{array}{l}\text { Random effects model } \\
\text { Heterogeneity: } I^{2}=86 \%, \tau^{2}=0.0315\end{array}$}} & $443 \underset{\Gamma \Pi}{\dot{j}}$ & & \multirow{2}{*}{\multicolumn{2}{|c|}{$13.61[4.78 ; 25.32]$}} & \multirow[t]{2}{*}{$100.0 \%$} \\
\hline & & \multicolumn{2}{|c|}{ 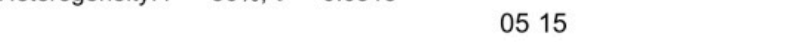 } & & & \\
\hline
\end{tabular}

Figure 3. Forest plot-adverse events.

Only one study reported the incidence of NODAT in post-LT patients [10]. In a prospective study involving 264 post-LT patients without a previous history of diabetes mellitus, incidence of NODAT was found to be significantly higher in the statin group as compared to the non-statin group ( $31.7 \%$ vs. $17.6 \%, p=0.03)$. Additionally, Mela et al. found no significant difference in the odds of graft failure found between the statin and no statin (OR $=0.96$; 95\% CI: 0.26-3.53, $p=0.96)$ [36].

\subsection{Lipids, Cardiovascular Events and Overall Mortality}

The total number of patients in this study with statin use in post-LT settings was 728 . In 177 patients, the overall mean decrease in total cholesterol (TC) levels after statin therapy 
was $-25.07 \mathrm{mg} / \mathrm{dL}$ (95\% CI: -81.28 to 31.153). In 92 patients, the overall mean decrease in low-density lipoprotein (LDL) levels was $-42.75 \mathrm{mg} / \mathrm{dL}$ (95\% CI: -19.28 to -66.22$)$. The pooled analysis showed decreased all-cause mortality with statin use $(\mathrm{HR}=0.282$; 95\% CI: 0.154-0.517, $p<0.001$. Mela et al. found that the incidence of CVS events was non-significantly lower in patients on statin compared to non-statin $(\mathrm{OR}=0.45 ; 95 \% \mathrm{CI}$ : $0.11-1.91, p=0.28)$ [36].

\title{
3.5. Graft Rejection and HCC Recurrence
}

Pooled analysis of 253 post-LT patients showed significantly decreased odds $(\mathrm{OR}=0.33$; 95\% CI: $0.15-0.73, p=0.007)$ of graft rejection in patients on statin. Cho et al. examined the association of statin therapy with HCC recurrence in 347 post-LT patients (statin, $n=112$; no statin, $n=235$ ) [39]. During a median follow-up duration of 44.9 months, statin treatment was associated with significantly lower recurrence risk of HCC after adjusting for other risk factors (HR $=0.32,95 \% \mathrm{CI}: 0.11-0.89)$.

\section{Discussion}

This systematic review and meta-analysis summarize the current evidence on the use of statins in post-LT patients (Figure 4), in line with published data of statin use in other solid organ transplant settings [15,16,18,41-43] (Table S1 in Supplementary Materials). In renal transplant patients, statin use was associated with decreased lipid levels [16] as well as a reduction in major adverse cardiac events and improved CVS mortality [42]. In the heart transplant population, the use of statins was associated with significant reduction in all-cause mortality, hemodynamically significant or fatal rejection, and incidence of coronary vasculopathy [18]. In our review, statins were not only found to be safe in postLT patients but decreased mortality, graft rejections and HCC recurrence. Statins were underutilized with only 32\% (95\% CI: 0.15-0.52) of 1094 eligible post-LT patients receiving a statin.

\section{Statin Use After Liver Transplant}

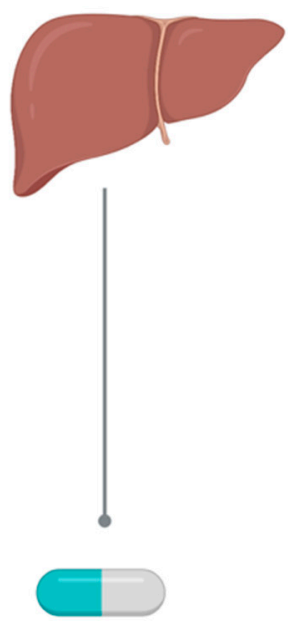

\author{
Adverse Reactions \\ Myopathy: $2 \% \quad$ Gl side effects: $1 \%$ \\ Myalgia: $5 \% \quad$ Nausea and vomiting: $3 \%$ \\ Pruritus: $1 \%$

\begin{tabular}{|c|c|}
\hline & $\begin{array}{l}\text { Graft Rejection: } \mathrm{OR}=0.33 \\
(0.15-0.73), p=0.007 \\
\text { HCC Recurrence: } \mathrm{HR}=0.32 \\
(0.11-0.89)\end{array}$ \\
\hline 窎 & $\begin{array}{l}\text { CVS Events: OR=0.45 }(0.11- \\
1.91), p=0.28 \\
\text { Mortality: } \mathrm{HR}=0.282(0.154- \\
0.157), p<0.001\end{array}$ \\
\hline
\end{tabular}

Figure 4. Visual illustration of statin benefits post LT.

The safety of statins was presented in a single arm analysis due to a lack of comparison between statins and no statins, with a total 14\% of patients experiencing an adverse event. Serious adverse events including rhabdomyolysis, hepatotoxicity and acute liver failure were not reported with statin use. Statins used outside the settings of LT can provide a gauge on the safety profile. In the Collaborative Atorvastatin Diabetes Study of 1428 individuals given atorvastatin, the rate of statin-related adverse events was $23 \%$. In 
a review for the U.S. Preventive Services Task Force, serious adverse events with statins varied from $0.9 \%$ to $34 \%$ [44]. In renal transplant recipients, statins had no significant effects on adverse events, including creatinine kinase or liver-enzyme elevation [42]. In the heart-transplant population, Som et al. found that $12.5 \%$ of patients on statins experienced adverse events (myalgia and myositis).

Cho et al. found increased risk of NODAT in post-LT patients with statin use [10]. In the non-transplant population, incident diabetes has also been reported before among non-diabetic patients taking statins $[45,46]$. Up to $25 \%$ of LT patients experience NODAT, and it is unclear if this is due to the statins or from confounding by patients having an increased cardiometabolic risk at baseline, and the onset of NODAT with statin use has not been described in other transplant studies [47].

Drug interactions are also a concern between statins and immunosuppressants in transplant patients $[9,34,35]$. Cyclosporine, a calcineurin inhibitor (CNI), was implicated previously in 2011 when the U.S. Food and Drug Administration (FDA) issued a warning regarding drug-drug interactions with statins, resulting in significant changes in statin prescription practices for dyslipidemic transplant recipients [48]. Tacrolimus, also a CNI, has largely replaced cyclosporine in this domain; despite several clinical guidelines still advising dose adjustments for both CNIs [48], tacrolimus appears to be a much safer option due to the lack of drug interactions with statins $[48,49]$.

Several studies substantiated the reduced incidence of CVS events and mortality with the use of statins $[8,44]$. In our meta-analysis, statin use was associated with decreased mortality rate post LT. Our results, however, did not find a significant reduction in CVS events with the use of statins [36], which is likely due to the small sample size reported in only one study [36]. Concordantly, studies in the renal and heart transplant setting have found that statins were associated with reduced CVS events $[18,41,42]$ and reduction in mortality $[15,18,42]$.

The odds of graft rejection and HCC recurrence were found to be decreased with the use of statins. Lower graft-rejection rates were also found to be significant in the renal transplant [15] and cardiac transplant [18] populations. Cho et al. reported that the use of statins $(n=347)$ was associated with a decreased risk of HCC recurrence. A meta-analysis estimated that up to $13 \%$ of HCC recurrence occurs after liver transplant [50]. Statins have been closely associated with anti-cancer properties, with antiproliferative, apoptosis induction and anti-invasive effects [39]. These properties may contribute to the observed benefit [51].

\section{Strengths and Limitations}

To our knowledge, this is the first review that summarizes the evidence of statin use in LT. We found that statins can be associated with decreased mortality, graft rejection and HCC recurrence without increasing the complications rate. However, this meta-analysis has some potential limitations. First, there were a limited number of studies available in LT. As such, only 11 articles were included, and a majority of these were retrospective studies. Due to the paucity of available data, we were unable to study the relationship between immunosuppressants and statins in post-LT patients, and the relationship between HCC and statin use was only reported in one study, as was the risk of NODAT. Next, the relationship between graft rejection and statin use might be confounded, as graft rejection mostly occurs in the first month post LT [52], but the average time to initiation of statins was beyond 1 month in studies included [11,37]. Third, indications for initiating statins in post-LT patients are varied, including high LDL level and the presence of diabetes mellitus, despite the increased risk of cardiovascular disease being the main reason. Next, a majority of the articles had incomplete data on patient follow-up and lacked strategies to address confounding, which limited our quality assessment. Moreover, our analysis of cholesterol change resulted in a wide $95 \%$ CI (-81.28 to 31.15). Despite the range crossing 0 , statistical significance is not associated with this parameter due to the lack of comparison in this single-armed analysis. Nonetheless, the wide CI could be a result of a lack of studies and 
small sample size. Lastly, we were unable to compare the use of different classes of statins (namely, hydrophilic and lipophilic) in the post-LT population due to the limited number of studies.

\section{Conclusions}

Preliminary evidence shows that statins appear to be safe and efficacious in the post-LT population, with added benefits such as reduced mortality, HCC recurrence and graft rejection. However, more high-quality, large-scale studies are needed to explore the possibility of development of NODAT with statin therapy. In addition, the effects of drug interactions of statins with immunosuppressants should be further evaluated.

Supplementary Materials: The following are available online at https:/ / www.mdpi.com/article/10 .3390 /transplantology2030025/s1, Table S1: Summary of meta-analyses.

Author Contributions: Y.J.H., A.S.-M.K. and Z.H.O. contributed to the acquisition of data, analysis and interpretation of data, and drafted the article. C.H.N., G.K., N.W.S.C., H.N.L., M.S.S. and M.D.M. aided in revising the article critically for important intellectual content. All authors have read and agreed to the published version of the manuscript.

Funding: This research did not receive any specific grant from funding agencies in the public, commercial, or not-for-profit sectors.

Institutional Review Board Statement: Not applicable.

Informed Consent Statement: Not applicable.

Data Availability Statement: All articles are available from Medline and Embase.

Conflicts of Interest: The authors declare no conflict of interest.

\section{References}

1. Laish, I.; Braun, M.; Mor, E.; Sulkes, J.; Harif, Y.; Ben Ari, Z. Metabolic syndrome in liver transplant recipients: Prevalence, risk factors, and association with cardiovascular events. Liver Transpl. 2011, 17, 15-22. [CrossRef] [PubMed]

2. Mells, G.; Neuberger, J. Reducing the risks of cardiovascular disease in liver allograft recipients. Transplantation 2007, 83, 1141-1150. [CrossRef] [PubMed]

3. Hüsing, A.; Kabar, I.; Schmidt, H.H. Lipids in liver transplant recipients. World J. Gastroenterol. 2016, 22, 3315-3324. [CrossRef]

4. Madhwal, S.; Atreja, A.; Albeldawdi, M.; Lopez, R.; Post, A.; Costa, M.A. Is liver transplantation a risk factor for cardiovascular disease? a meta-analysis of observational studies. Liver Transpl. 2012, 18, 1140-1146. [CrossRef] [PubMed]

5. Kim, N.G.; Sharma, A.; Saab, S. Cardiovascular and metabolic disease in the liver transplant recipient. Best Pract. Res. Clin. Gastroenterol. 2020, 46-47, 101683. [CrossRef]

6. Fatourou, E.M.; Tsochatzis, E.A. Management of metabolic syndrome and cardiovascular risk after liver transplantation. Lancet Gastroenterol. Hepatol. 2019, 4, 731-741. [CrossRef]

7. Bagley, J.; Williams, L.; Hyde, M.; Birriel, C.R.; Iacomini, J. Hyperlipidemia and Allograft Rejection. Curr. Transplant Rep. 2019, 6, 90-98. [CrossRef]

8. Bibbins-Domingo, K.; Grossman, D.C.; Curry, S.J.; Davidson, K.W.; Epling, J.W.; García, F.A.; Gillman, M.W.; Kemper, A.R.; Krist, A.H.; Kurth, A.E.; et al. Statin use for the primary prevention of cardiovascular disease in adults: US preventive services task force recommendation statement. JAMA J. Am. Med. Assoc. 2016, 316, 1997-2007.

9. Martin, J.E.; Cavanaugh, T.M.; Trumbull, L.; Bass, M.; Weber, F.; Jr Aranda-Michel, J. Incidence of adverse events with HMG-CoA reductase inhibitors in liver transplant patients. Clin. Transpl. 2008, 22, 113-119. [CrossRef]

10. Cho, Y.; Lee, M.J.; Choe, E.Y.; Jung, C.H.; Joo, D.J.; Kim, M.S. Statin therapy is associated with the development of new-onset diabetes after transplantation in liver recipients with high fasting plasma glucose levels. Liver Transpl. 2014, 20, 557-563. [CrossRef]

11. Selim, R.; Abdulhamid, A.; Shyamraj, A.; Watson, A.; Tang, J.; Jafri, S.M. Statins in liver transplant recipients: Rates of use, mortality and rejection. Am. J. Transpl. 2017, 17, 585.

12. Tan, P.S.; Muthiah, M.; Koh, T.; Teoh, Y.; Chan, A.; Kow, A. Asian Liver Transplant Network Clinical Guidelines on Immunosuppression in Liver Transplantation. Transplantation 2018, 103, 1. [CrossRef]

13. Patel, S.S.; Guzman, L.A.; Lin, F.-P.; Pence, T.; Reichman, T.; John, B. Utilization of aspirin and statin in management of coronary artery disease in patients with cirrhosis undergoing liver transplant evaluation. Liver Transpl. 2018, 24, 872-880. [CrossRef] [PubMed]

14. Campbell, P.T.; VanWagner, L.B. Mind the Gap: Statin Underutilization and Impact on Mortality in Liver Transplant Recipients. Liver Transpl. Soc. 2019, 25, 1477-1479. [CrossRef] [PubMed] 
15. Rostami, Z.; Arani, M.; Salesi, M.; Safiabadi, M.; Einollahi, B. Effect of Statins on Patients and Graft Survival in Kidney Transplant Recipients: A Survival Meta-analysis. Iran. J. Kidney Dis. 2017, 11, 329-338.

16. Huang, X.; Jia, Y.; Zhu, X.; Zhang, Y.; Jiang, L.; Wei, X. Effects of Statins on Lipid Profile of Kidney Transplant Recipients: A Meta-Analysis of Randomized Controlled Trials. BioMed. Res. Int. 2020, 9094543.

17. Mehra, M.R.; Raval, N.Y. Metaanalysis of statins and survival in de novo cardiac transplantation. Transplant Proc. 2004, 36, 1539-1541. [CrossRef]

18. Vallakati, A.; Reddy, S.; Dunlap, M.E.; Taylor, D.O. Impact of Statin Use After Heart Transplantation: A Meta-Analysis. Circ. Heart Fail. 2016, 9, 10. [CrossRef] [PubMed]

19. Blais, P.; Lin, M.; Kramer, J.R.; El-Serag, H.B.; Kanwal, F. Statins Are Underutilized in Patients with Nonalcoholic Fatty Liver Disease and Dyslipidemia. Dig. Dis. Sci. 2016, 61, 1714-1720. [CrossRef] [PubMed]

20. Almutairi, F.; Peterson, T.C.; Molinari, M.; Walsh, M.J.; Alwayn, I.; Peltekian, K.M. Safety and effectiveness of ezetimibe in liver transplant recipients with hypercholesterolemia. Liver Transpl. 2009, 15, 504-508. [CrossRef]

21. Loffredo, L.; Pastori, D.; Farcomeni, A.; Violi, F. Effects of Anticoagulants in Patients with Cirrhosis and Portal Vein Thrombosis: A Systematic Review and Meta-analysis. Gastroenterology 2017, 153, 480-487.e1. [CrossRef]

22. Sedgwick, P. What is publication bias in a meta-analysis? BMJ Br. Med. J. 2015, 351, h4419. [CrossRef] [PubMed]

23. Hopewell, S.; McDonald, S.; Clarke, M.J.; Egger, M. Grey literature in meta-analyses of randomized trials of health care interventions. Cochrane Database Syst. Rev. 2007. [CrossRef]

24. McKenzie, J.E.; Brennan, S.E.; Ryan, R.E.; Thomson, H.J.; Johnston, R.V.; Thomas, J. Defining the criteria for including studies and how they will be grouped for the synthesis. Cochrane Handb. Syst. Rev. Int. 2019, 3, 33-65.

25. Wan, X.; Wang, W.; Liu, J.; Tong, T. Estimating the sample mean and standard deviation from the sample size, median, range and/or interquartile range. BMC Med. Res. Methodol. 2014, 14, 135. [CrossRef] [PubMed]

26. Furukawa, T.A.; Barbui, C.; Cipriani, A.; Brambilla, P.; Watanabe, N. Imputing missing standard deviations in meta-analyses can provide accurate results. J. Clin. Epidemiol. 2006, 59, 7-10. [CrossRef] [PubMed]

27. Nyaga, V.N.; Arbyn, M.; Aerts, M. Metaprop: A Stata command to perform meta-analysis of binomial data. Arch. Public Health 2014, 72, 39. [CrossRef]

28. DerSimonian, R.; Laird, N. Meta-analysis in clinical trials. Control Clin. Trials. 1986, 7, 177-188. [CrossRef]

29. Harris, R.; Bradburn, M.; Deeks, J.; Harbord, R.; Altman, D.; Sterne, J. Metan: Fixed and random-effects meta-analysis. Stata J. 2008, 8, 3-28. [CrossRef]

30. Fletcher, J. What is heterogeneity and is it important? BMJ 2007, 334, 94-96. [CrossRef]

31. Aromataris, E.; Fernandez, R.; Godfrey, C.M.; Holly, C.; Khalil, H.; Tungpunkom, P. Summarizing systematic reviews: Methodological development, conduct and reporting of an umbrella review approach. Int. J. Evid. Based Healthc. 2015, 13, 132-140. [CrossRef] [PubMed]

32. Borges Migliavaca, C.; Stein, C.; Colpani, V.; Barker, T.H.; Munn, Z.; Falavigna, M. How are systematic reviews of prevalence conducted? A methodological study. BMC Med. Res. Methodol. 2020, 20, 96. [CrossRef] [PubMed]

33. Imagawa, D.K.; Dawson Iii, S.; Holt, C.D.; Kirk, P.S.; Kaldas, F.M.; Shackleton, C.R. Hyperlipidemia after liver transplantation: Natural history and treatment with the hydroxy-methylglutaryl-coenzyme A reductase inhibitor pravastatin. Transplantation 1996, 62, 934-942. [CrossRef] [PubMed]

34. Zachoval, R.; Gerbes, A.L.; Schwandt, P.; Parhofer, K.G. Short-term effects of statin therapy in patients with hyperlipoproteinemia after liver transplantation: Results of a randomized cross-over trial. J. Hepatol. 2001, 35, 86-91. [CrossRef]

35. Taylor, P.J.; Kubler, P.A.; Lynch, S.V.; Allen, J.; Butler, M.; Pillans, P.I. Effect of Atorvastatin on Cyclosporine Pharmacokinetics in Liver Transplant Recipients. Ann. Pharmacother. 2004, 38, 205-208. [CrossRef] [PubMed]

36. Mela, M.; Gelson, W.; Unitt, E.; Alexander, G. Statins before and after liver transplantation-A randomised control trial with 5-year follow-up. J. Hepatol. 2011, 54, S227-S228. [CrossRef]

37. Glynn, M.; Jantz, A.; Summers, B.; Salgia, R.; Sulejmani, N. Safety of statin therapy after liver transplantation. Am. J. Transpl. 2017, 17,585 .

38. Campbell, P.T.; Kosirog, M.; Montag, S.; Connolly, S.; Daud, A.; Das, A. Guideline adherence for secondary prevention of stroke and atherosclerotic cardiovascular disease among liver transplant recipients. Am. J. Transpl. 2019, 19, 864.

39. Cho, Y.; Kim, M.S.; Nam, C.M.; Kang, E.S. Statin Use is Associated with Decreased Hepatocellular Carcinoma Recurrence in Liver Transplant Patients. Sci. Rep. 2019, 9, 1467. [CrossRef] [PubMed]

40. Patel, S.S.; Rodriguez, V.A.; Siddiqui, M.B.; Faridnia, M.; Lin, F.-P.; Chandrakumaran, A. The Impact of Coronary Artery Disease and Statins on Survival after Liver Transplantation. Liver Transpl. Soc. 2019, 25, 1514-1523. [CrossRef]

41. Hwang, S.D.; Lee, J.H.; Jhee, J.H.; Kim, Y.J.; Park, K.M.; Kim, J.K. Effect of Fluvastatin on Cardiovascular Complications in Kidney Transplant Patients: A Systemic Review and Meta-analysis. Transpl. Proc. 2019, 51, 2710-2713. [CrossRef]

42. Palmer, S.C.; Navaneethan, S.D.; Craig, J.C.; Perkovic, V.; Johnson, D.W.; Nigwekar, S.U. HMG CoA reductase inhibitors (statins) for kidney transplant recipients. Cochrane Database Syst. Rev. 2014, 1, 5019. [CrossRef]

43. Som, R.; Morris, P.J.; Knight, S.R. Graft vessel disease following heart transplantation: A systematic review of the role of statin therapy. World J. Surg. 2014, 38, 2324-2334. [CrossRef]

44. Chou, R.; Dana, T.; Blazina, I.; Daeges, M.; Jeanne, T.L. Statins for Prevention of Cardiovascular Disease in Adults: Evidence Report and Systematic Review for the US Preventive Services Task Force. JAMA 2016, 316, 2008-2024. [CrossRef] [PubMed] 
45. Saliba, F.; Lakehal, M.; Pageaux, G.P.; Roche, B.; Vanlemmens, C.; Duvoux, C. Risk factors for new-onset diabetes mellitus following liver transplantation and impact of hepatitis C infection: An observational multicenter study. Liver Transpl. 2007, 13, 136-144. [CrossRef] [PubMed]

46. Sattar, N.; Preiss, D.; Murray, H.M.; Welsh, P.; Buckley, B.M.; de Craen, A.J. Statins and risk of incident diabetes: A collaborative meta-analysis of randomised statin trials. Lancet 2010, 375, 735-742. [CrossRef]

47. Chin, Y.H.; Tan, H.Q.M.; Ng, C.H.; Tan, D.J.H.; Lin, S.Y.; Huang, D.Q.; Khoo, C.M.; Muthiah, M.D. A Time-Based Meta-Analysis on the Incidence of New Onset Diabetes after Liver Transplantation. J. Clin. Med. 2021, 10, 1045. [CrossRef]

48. Migliozzi, D.R.; Asal, N.J. Clinical Controversy in Transplantation: Tacrolimus Versus Cyclosporine in Statin Drug Interactions. Ann. Pharmacother. 2020, 54, 171-177. [CrossRef]

49. Lemahieu, W.P.; Hermann, M.; Asberg, A. Combined therapy with atorvastatin and calcineurin inhibitors: No interactions with tacrolimus. Am. J. Transplant. 2005, 5, 2236-2243. [CrossRef]

50. Tan, D.J.H.; Wong, C.; Ng, C.H. A Meta-Analysis on the Rate of Hepatocellular Carcinoma Recurrence after Liver Transplant and Associations to Etiology, Alpha-Fetoprotein, Income and Ethnicity. J. Clin. Med. 2021, 10, 238. [CrossRef]

51. Pradelli, D.; Soranna, D.; Scotti, L.; Zambon, A.; Catapano, A.; Mancia, G. Statins and primary liver cancer: A meta-analysis of observational studies. Eur. J. Cancer Prev. 2013, 22, 229-234. [CrossRef] [PubMed]

52. Dogan, N.; Hüsing-Kabar, A.; Schmidt, H.H.; Cicinnati, V.R.; Beckebaum, S.; Kabar, I. Acute allograft rejection in liver transplant recipients: Incidence, risk factors, treatment success, and impact on graft failure. J. Int. Med. Res. 2018, 46, 3979-3990. [CrossRef] [PubMed] 